\title{
CONGO
}

\section{ADHÉSION A LA CONVENTION DE GENÈVE}

Circulaire adressée aux gouvernements signataires de la Contention de Genève.

LE CONSEIL FÉdÉral DE LA CONFÉdÉRATION SUISSE

Vu la déclaration, datée de Bruxelles le 27 décembre 1888, par laquelle Son Excellence Monsieur l'administrateur général du département des affaires étrangères de l'Etal indépendant du Congo, dúment autorisé par son souverain, et faisant usage de la faculté réservée à l'article neuf de la convention internationale conclue à Genève le 22 aoùt 1864 pour l'amélioration du sort des militaires blessés dans les armées en campagne, déclare que le gouvernement de l'Etat indépendant du Congo accède à cette convention,

\section{DÉCLARATION DONT LA TENEUR SUIT :}

( Le gouvernement de l'Etat indépendant du Congo, désirant prendre rang dans la Société internationale de la Croix-Rouge, et ayant pris connaissance de la convention conclue à Genève le 22 août 1864, entre la Confédération suisse et plusieurs autres Etats, pour l'amélioration du sort des militaires blessés dans les armées en campagne, convention dont la teneur suit:

\section{(Inseratur)}

(Le soussigné, administrateur général du département des affaires étrangères de l'Etat indépendant du Congo, dủment autorisé à cet effet par son auguste souverain, Léopold II, roi des Belges, souverain de l'Etat indépendant du Congo, déclare par les présentes que le gouvernement de l'Elat indépendant du Congo accède complètement à la susdite convention.

" En foi de quoi, il a signé le présent acte d'accession et y a apposé le sceau de l'Etat.

"Fait à Bruxelles, le vingt-sept décembre mil huit cent quatrevingt-huit. »)

(signé) Edm. vax Eetvelde

L. S. 


\section{1}

DÉCLARE PAR LES FRÉSENTES :

En vertu de la disposition finale du procès-verbal d'échange des ratifications de la dile convention, signé à Berne le vingt-deux décembre mil huit cent soixante-quatre, accepter cette adhésion, tant au nom de la Confédération suisse qu'en celui des autres Etats contractants, auxquels acte en est donné par la présente déclaration.

EN FOI DE QUOI,

Les présentes ont été signées par le président et le chancelier de la Confédération suisse el munies du sceau du Conseil fédéral, à Berne, le vingt-cinq janvier mil huit cent quatre-vingt-neuf (25 janvier 1889).

AU NOM DU CONSEIL FÉDÉRẠL SUISSE :

Le président de la Confédération, HAMMER

Le chancelier de la Confédération,

Ringier

\section{STATUTS DE L'ASSOCIATION CONGOLAISE ET AFRICAINE DE LA}

\section{CROIX-ROUGE}

ARTICLE PREMIER.

L'Association a pour but principal de secourir les soldats et sujets congolais malades ou blessés en temps de guerre, et, en tout temps, de prêter aide et assistance, dans la mesure de ses ressources et dans toute l'étendue de l'Afrique:

$1^{\circ} \Lambda$ tous ceux qui, s'étant dévoués aux intérêt de la civilisation en Afrique, sont atteints de blessures ou de maladies;

$2^{\circ}$ Aux indigènes malades ou blessés.

Elle pourra établir en Afrique ot y posséder des sanatorium, des hospices, des refuges ou autres établissements, et faire, d'une manière générale, toutes opérations qui seront de nature à lui faciliter la réalisation de son objet.

Elle entretient des relations régulières avec les antres sociétés nationales de la Croix-Rouge et avec le Comité international qui siège à Genève.

Elle pourra, en outre, s'affilier à des associations ayant un but similaire 